\title{
PENGATURAN PUTARAN DUA MOTOR STEPPER MELALUI LPT1
}

\author{
Riyanto $^{\prime}$, Yuneli Wikundhari ${ }^{2}$ \\ ${ }^{1.2}$ Program Studi Diploma III Teknik Telekomunikasi, Purwokerto \\ 'riyanto@akatelsp.ac.id, ${ }^{2}$ yunelly_maniezzz@yahoo.co.id
}

\begin{abstract}
Existence of complication various industrial electronic system can cause to go down the result of industry. Hereinafter, intention of this final project is visual language application of basic for the application at a band conveyor system industry or factory so that water down in control of produced goods. Here visual language of basic used as control instruct rotation from stepper motor [pass/through] a PC. Here used PC only one, this matter because of to be more performance efficiency from the system easier so that in the case of observation and also control.
\end{abstract}

Keywords: Motor Stepper, Visual Basic 6.0, Parallel Port

\section{Pendahuluan}

Salah satu keinginan setiap orang adalah merasakan kemudahan dalam kegiatan sehari - hari, sehingga orang berfikir untuk membuat suatu alat yang dapat meringankan kegiatannya tanpa menguras tenaga, dan dapat memantau kinerja alat tersebut dengan perangkat lunak pada PC.

PC atau Personal Computer. Secara definisi komputer diterjemahkan sebagai sekumpulan alat elektronik yang saling bekerjasama, dapat menerima data (input), mengolah data (proses) dan memberikan informasi (output) serta terkoordinasi dibawah kontrol program yang tersimpan di memorinya. PC merupakan jenis komputer yang dipakai untuk perorangan, bentuk dari PC relatif lebih kecil dibandingkan dengan komputer generasi sebelumnya yaitu main frame. Besar main frame adalah satu ruangan penuh.

Pada PC terdapat dua buah port yaitu port serial dan port parallel. Port serial ialah pengiriman data secara serial (data dikirim satu per satu secara berurutan), sehingga komunikasi serial jauh lebih lambat daripada komunikasi paralel. Port serial lebih sulit ditangani karena peralatan yang dihubungkan ke port serial harus berkomunikasi dengan menggunakan 
transmisi serial, sedang data di komputer diolah secara parallel. Oleh karena itu data dari dan ke serial port harus dikonversikan ke dan dari bentuk parallel untuk bisa digunakan. Port parallel ialah port data di komputer untuk mentransmisi 8 bit data dalam sekali detak.

Pada pengaturan putaran motor stepper melalui LPT1. Perangkat lunak yang digunakan adalah bahasa pemrograman microsoft visual basic 6.0 .

\section{Metode Penelitian}

\section{A. Hardware}

Sistem pengendalian motor stepper terdiri dari beberapa perangkat keras yang akan mendukung kinerja program yang sudah disusun. Adapun secara garis besar gambaran keseluruhan sistem kendali motor stepper menggunakan Visual Basic 6.0 adalah sebagai berikut:

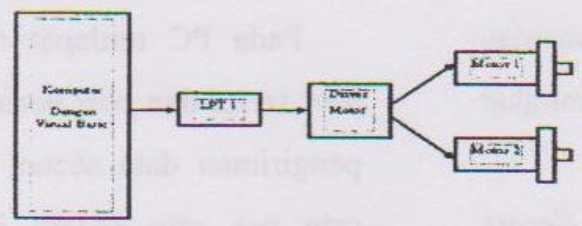

Gambar 1. Diagram blok pengendali motor stepper

\section{Komputer yang Dilengkapi}

\section{Program Visual Basic 6.0}

Komputer merupakan pusat pengendalian yang akan mengendalikan rangkaian berdasarkan perintah software motor stepper yang terdapat pada program Visual Basic 6.0. Komputer tidak boleh padam bila pengendalian harus dilakukan dalam waktu yang lama. Bila komputer padam maka secara otomatis program pengendalian yang sedang berjalan akan terhenti.

\section{LPT (Line Printer)}

Untuk menghubungkan antara komputer dengan perangkat kendali digunakanlah port parallel. Komunikasi yang terjadi hanya satu arah saja dimana komputer akan mengirimkan data ke perangkat kendali dan tidak bisa membaca data dari perangkat kendali.

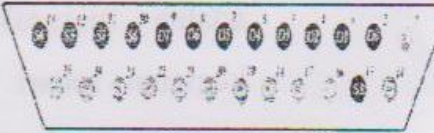

Gambar 2. Pin Konektor DB-25

Alamat port yang digunakan adalah 888 atau alamat LPT 1, dan jalur yang digunakan adalah jalur data dimana ada delapan jalur data yang digunakan yaitu D0-D7.

Suatu port berisi satu set sinyal dari CPU yang mengirimkan atau menerima data dengan komponen lain. Didalam pemberian sinyal, sinyal start adalah 
"I" dan sinyal stop adalah "0" seperti sistem biner.

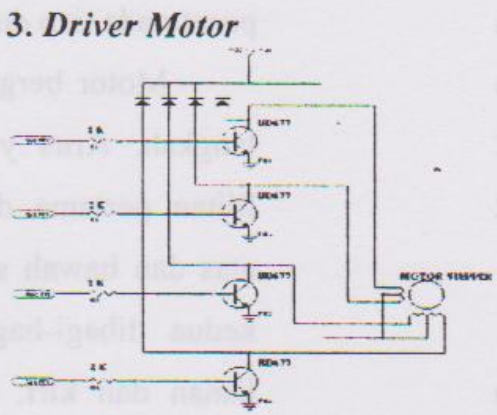

Gambar 3. Rangkaian pengatur putaran motor stepper

Elemen penyusun rangkaian kendali:

a. 8 Buah Resistor $2 \mathrm{~K}$

Gambar 4. Resistor 2K

Maka nilai resistansinya: Gelang merah nilainya $=2$ dan gelang hitam nilainya $=0$. Jadi satuannya adalah 20. Gelang ketiga adalah faktor pengali, dan jika warna gelangnya merah berarti faktor pengalinya adalah 100 . Sehingga nilai resistansi resistor tersebut adalah nilai satuan $\mathrm{x}$ faktor pengali atau $20 \times 100=2 \mathrm{~K}$ Ohm dan toleransinya adalah $5 \%$.

Rangkaian

Kendali

menggunakan 8 buah Resistor $2 \mathrm{~K}$

Ohm yang terhubung dengan pin 2 sampai pin 9 port parallel. Resistor berfungsi sebagai memperkecil arus yang akan masuk ke basis transistor BD139 karena arus yang diperiukan oleh basis agar Transistor sangat kecil.

\section{b. 8 Buah Transistor BD139 (NPN)}

8 buah Transistor BD139 yang berfungsi sebagai saklar. Kerja motor stepper akan tergantung dari ada tidaknya arus yang masuk ke basis Transistor BD139. Bila tidak ada arus yang masuk ke basis, maka motor stepper tidak akan bekerja. Sedangkan bila ada arus yang masuk ke basis maka motor akan bekerja.

Transistor BD 139 merupakan transistor power, khusus untuk transistor power sangat perlu untuk mengetahui spesifikasi $P_{D} \max$. Spesifikasi ini menunjukkan temperatur kerja maksimum yang diperbolehkan agar transistor masih bekerja normal. Sebab jika transistor bekerja melebihi kapasitas daya $P_{D} \max$, maka transistor dapat rusak atau terbakar.

c. 8 Buah Dioda $1000 \mathrm{~A}$

Dioda ini bertugas untuk mengendalikan tegangan balik dari motor.

d. VCC (Power Supply) 
Motor stepper membutuhkan tegangan yang stabil agar dapat tetap bekerja. Saat ini keperluan untuk membuat regulator, telah tersedia IC khusus seperti 7812 untuk regulator tegangan positif 12 VDC.

e. Printed Circuit Board (PCB)

Jenis PCB yang digunakan adalah PCB gambar, PCB ini dipilih dengan alasan kerapian rangkaian.

\section{Motor Stepper}

\section{a. Jenis Unipolar Motor}

Stepper motor terdiri dari berbagai ukuran dan jenis, dimulai dari disket motor kecil samapai permesinan yang sangat besar. Motor stepper yang digunakan untuk Tugas Akhir ini berjumlah dua buah dan kedua-duanya berjenis unipolar motor. Hal ini dikarenakan langkah unipolar motor yang mudah untuk diamati, dan kedua motor memiliki satu pusat lilitan sebagai pengubung ke power supply.
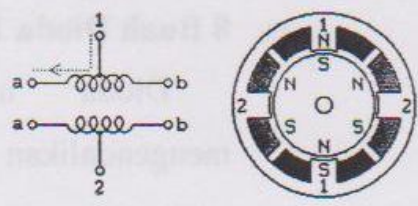

Gambar 5. Motor Stepper jenis unipolar

Kutup unipolar stepper motor, kedua-duanya Maknit tetap. Dan menggunakan 5 atau 6 kawat. Gambar 3.9, dengan satu pusat pada tiap dua lilitan.

Motor bergerak 30 derajat tiap langkah. Arus yang mengalir pada lilitan pertama dibagi-bagikan pada atas dan bawah stator, sedang lilitan kedua dibagi-bagikan antara motor kanan dan kiri. Rotor adalah suatu maknit tetap dengan 6 kutub, 3 selatan dan 3 utara, yang diatur di sekitar circumfrence nya.

Karena resolusi sudut motor lebih tinggi, rotor harus mempunyai perbandingan lebih sedikit yaitu 30 derajat.

\section{b. Sudut Putar Motor Stepper}

Motor stepper merupakan satusatunya jenis motor yang bekerja secara digital (sesuai masukan pulsa logika) Tiap masukan pulsa logika dapat menghasilkan satu langkah pada motor stepper. Sehingga dalam 1 revolusi tiap langkah motor stepper dapat dihitung sudutnya:

\section{Sudut $=360^{\circ} / \mathrm{n}$ rotor}

Besar sudut putar motor stepper tergantung dari jumlah rotor yang menyusunnya. Karena jenis motor stepper berbeda-beda, maka jumlah rotornya juga berbeda-beda. 
Motor stepper hanya berhenti setelah jumlah pulsa sudah tercapai, sehingga motor stepper tidak perlu rangkaian pengereman.

\section{c. Kecepatan Motor Stepper}

Kecepatan dalam motor stepper mempunyai range yang sangat lebar, sesuai dengan jumlah rotor yang menyusunnya. Motor stepper dirancang mampu berjalan mencapai panas diantara $\left(50^{\circ}-90^{\circ} \mathrm{C}\right)$. Bagaimanapun, terlalu banyak putaran dan semakin cepat putaran motor stepper menyebabkan pemanasan berlebihan dan kerusakan pada isolasi motor dan lilitan.

Kecepatan dari putaran batang motor stepper secara langsung dihubungkan dengan frekwensi dari pulsa masukan dalam satu putaran dan panjang perputaran sesuai dengan banyaknya pulsa masukan. Urutan pulsa diterapkan secara langsung dengan dihubungkan ke arah putaran batang motor.

\section{B. Software Motor Stepper}

Software merupakan bagian komputer yang menangani pengolahan data gerakan motor stepper. Untuk dapat melakukan pengendalian, maka diperlukan software yang sesuai dengan keperluan tersebut. Hubungan antara input, output dan software dapat dilihat pada gambar di bawah ini:

\section{Form Utama}

Untuk membangun software pengendali, digunakan bahasa pemrograman Visual Basic 6.0. adapun komponen-komponen dari bahasa pemrograman yang dipakai adalah sebagai berikut:

\section{a.FormI}

Form merupakan tempat untuk meletakkan komponen program yang digunakan sesuai dengan kebutuhan dari pembuat program.

\section{b.Tombol Perintah (Command Button)}

Komponen ini berfungsi untuk mengeksekusi perintah apabila tombol perintah diklik. Ada 3 tombol perintah yang digunakan dalam program ini yakni KANAN, KIRI dan BERHENTI. Adapun fungsi dari masing-masing tombol perintah dapat dilihat sebagai berikut:

\section{1) KANAN}

Perintah ini digunakan untuk mengendalikan kedua motor ke arah kanan dengan waktu tunda 
dan jumlah langkah yang telah ditentukan.

2) KIRI

Perintah ini digunakan untuk mengendalikan kedua motor ke arah kiri dengan waktu tunda dan jumlah langkah yang telah ditentukan.

\section{3) BERHENTI}

Tombol ini digunakan apabila pengguna program ingin menghentikan gerak kedua motor secara tiba-tiba, dengan catatan option manual telah dipilih.

\section{c. Label}

Dalam program ini terdapat 3 label yang digunakan untuk menampilkan informasi yang berasal dari program itu sendiri. Adapun fungsi dari masing-masing label tersebut:

1) Label1 berfungsi untuk menginformasikan label Waktu Tunda

2) Label2 berfungsi untuk menginformasikan label

\section{Jumlah Langkah}

3) Label3 berfungsi untuk menginformasikan label Arah Gerak

\section{d.Kotak Teks (Text Box)}

Komponen ini berfungsi untuk menampilkan isi teks pada saat program tersebut sedang digunakan. Perbedaan antara kotak teks dengan label adalah label menampilkan teks yang terdapat dalam properti caption, sedangkan kotak teks menampilkan teks yang terdapat dalam properti teks. Ada 2 kotak teks yang digunakan dalam program ini yaitu:

1) Txt1 berfungsi untuk menampilkan waktu tunda putaran motor.

2) Txt2 berfungsi untuk menampilkan jumlah langkah motor.

\section{e. Option Button}

Dalam program ini optionbutton yang digunakan untuk menjalankan pengendalian rangkaian motor stepper. Ada 2 optionbutton yang digunakan:

1) Otomatis yang berfungsi untuk menggerakan motor secara otomatis sesuai dengan jumlah langkah motor dan kecepatan motor yang telah ditentukan. Motor tidak akan berhenti sampai nilai jumlah langkah motor yang ditentukan.

2) Manual yang berfungsi untuk menggerakan motor secara manual, sesuai dengan jumlah langkah motor dan kecepatan motor yang telah ditentukan. Motor akan berhenti jika tombol berhenti ditekan.

\section{f. Inpout32.dll}

Komponen ini berfungsi sebagai antarmuka antara rangkaian kendali 
dengan komputer yang terhubung menggunakan port parallel. Komponen ini dapat di-download dari internet. Setelah mendapatkan file ini maka harus disalin ke folder $C:$ windows/system agar dapat digunakan.

Setelah komponen-komponen tersebut dikumpulkan pada form program maka tampilan program adalah sebagai berikut:

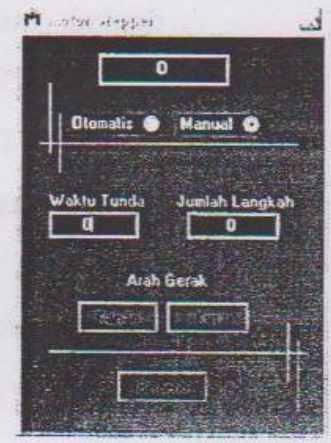

Gambar 6. Form Utama

\section{Hasil Dan Pembahasan}

\section{A. Perangkat Keras}

Setelah selesai merancang hardware dan software, maka selanjutnya kedua komponen ini akan diuji apakah dapat bekerja seperti yang diingin atau tidak. Setelah pengujian menunjukkan hasil yang baik, maka didapat suatu alat yang siap dijalankan untuk mengendalikan motor stepper dari jarak dekat yang menggunakan simulasi kendali dengan menggunakan software motor stepper yang telah dibuat.

Hasil dari perancangan alat pengendali motor stepper melalui LPTI dapat dilihat pada gambar di bawah ini:

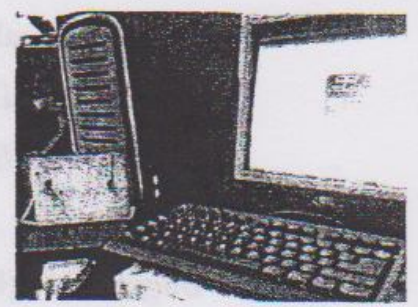

Gambar 7. Bagian Sisi Pengendalian

\section{Perangkat}

Pada gambar di atas menunjukkan bahwa peralatan kendali terdiri dari 2 bagian yaitu bagian pertama adalah pusat kendali yakni komputer berfungsi untuk mengirim data perintah pengaturan pengendalian menggunakan simulasi dengan mengetikkan jumlah langkah dan waktu delay putaran motor stepper pada software motor stepper yang telah dibuat, yang kedua adalah rangkaian pengendali yakni bagian yang menerima output pengendali dari pusat pengendalian berupa kombinasi bit biner hasil terjemahan data dari komputer yang mengendalikan arah putar, waktu delay, dan langkah motor stepper.

\section{B. Bagian Pusat Pengendali (Komputer)}

Pada gambar di atas terlihat bahwa komputer digunakan sebagai pusat 
2) Tampilan program seperti ditunjukan oleh gambar 6 akan muncul setelah icon di clik.

3) Memilih mode yang digunakan "MANUAL" atau "OTOMATIS" sesuai kebutuhan.

Jika mode otomatis dipilih maka jumlah langkah motor stepper yang terakhir atau maksimal akan sesuai dengan jumlah yang ada pada kotak "Jumlah Langkah" dan dalam hal ini tombol berhenti tidak berfungsi.

Dalam mode manual, kotak "Jumlah Langkah" tidak terlihat. Dikarenakan pada mode manual "Jumlah Langkah" tidak diperlukan, motor akan melangkah dengan jumlah yang tidak tentu, motor hanya akan berhenti stelah tombol "Berhenti" ditekan.

4) Untuk keluar dari program, adalah dengan cara menekan tombol close pada ujung kanan tampilan halaman program, maka secara otomatis program akan ditutup.

\section{E. Hasil Percobaan}

\section{Hasil percobaan pengendalian}

Dari hasil percobaan yang telah dilakukan, pada motor stepper baik menggunakan mode otomatis maupun mode manual memiliki hasil yang sama. Pada percobaan ini digunakan "Waktu tunda" 0.8 dan "Jumlah langkah" manual 10, sedangkan untuk mode otomatis saat motor mencapai langkah ke 8 tombol berhenti ditekan sehingga motor secara otomatis berhenti pada langkah ke 9 .

\section{a. Ke arah kanan}

Tabel 4.I Tabel hasil pengamatan gerak motor ke arah kanan

\begin{tabular}{|c|c|c|}
\hline $\begin{array}{l}\text { KONDI } \\
\text { SI }\end{array}$ & BINER & $\begin{array}{c}\text { DESIM } \\
\text { AL }\end{array}$ \\
\hline \multirow[t]{2}{*}{0} & 0000.00 & 0 \\
\hline & 00 & \\
\hline \multirow[t]{2}{*}{1} & 0001.00 & 17 \\
\hline & 01 & \\
\hline \multirow[t]{2}{*}{2} & 0010.00 & 34 \\
\hline & 10 & \\
\hline \multirow[t]{2}{*}{3} & 0100.01 & 68 \\
\hline & 00 & \\
\hline \multirow[t]{2}{*}{4} & 1000.10 & 136 \\
\hline & 00 & \\
\hline \multirow[t]{2}{*}{5} & 0001.00 & 17 \\
\hline & 01 & \\
\hline \multirow[t]{2}{*}{6} & 0010.00 & 34 \\
\hline & 10 & \\
\hline \multirow[t]{2}{*}{7} & 0100.01 & 68 \\
\hline & 00 & \\
\hline 8 & 1000.10 & 136 \\
\hline
\end{tabular}


00

\begin{tabular}{ccc}
\hline KONDISI & BINER & DESIMAL \\
\hline 0 & 0000.0000 & 0 \\
\hline 1 & 1000.1000 & 136 \\
\hline 2 & 0100.0100 & 68 \\
\hline 3 & 0010.0010 & 34 \\
\hline 4 & 0001.0001 & 17 \\
\hline 5 & 1000.1000 & 136 \\
\hline 6 & 0100.0100 & 68 \\
\hline 7 & 0010.0010 & 34 \\
\hline 8 & 0001.0001 & 17 \\
\hline 9 & 1000.1000 & 136 \\
\hline 10 & 0100.0100 & 68
\end{tabular}

$\begin{array}{lll}9 & 0001.00 & 17\end{array}$

01

$\begin{array}{lll}10 & 0010.00 & 34\end{array}$

10

Karena pengendalian ini menggunakan kkedua motor maka deklarasi logika untuk kedua motor binernya digabungkan.

Motor 1 untuk kondisi pertama $=0000.0001$ atau 1

Motor 2 untuk kondisi pertama $=0001.0000$ atau 16 Maka agar dapat menggerakan keduanya secara bersamaan maka jumlahkan keduanya sehingga didapat $=$
0001.0001 atau 17. Sedangkan untuk kondisi selanjutnya tambahkan nilai 17 pada kondisi sebelumnya, untuk seterusnya akan didapat perputaran kedua motor secara bersama-sama ke arah kanan.

\section{b. Ke arah kiri}

Tabel 4.2 Tabel hasil pengamatan gerak motor ke arah kiri

Karena pengendalian ini menggunakan kedua motor maka deklarasi logika untuk kedua motor binernya digabungkan.

Motor 1 untuk kondisi pertama $=$ 0000.1000 atau 8

Motor 2 untuk kondisi pertama $=$ 1000.0000 atau 128

Maka agar dapat menggerakan keduanya secara bersamaan maka jumlahkan keduanya sehingga didapat $=1000.1000$ atau 136 . Sedangkan untuk kondisi selanjutnya kurangi nilai 17 pada kondisi sebelumnya, untuk seterusnya akan didapat perputaran kedua motor secara bersama-sama ke arah kiri. 


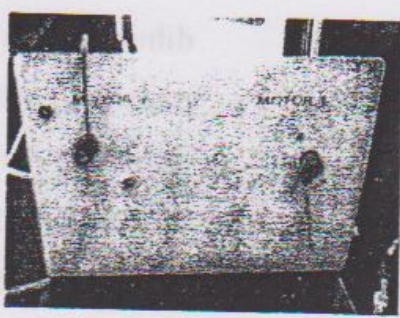

Gambar 9. Saat perangkat dalam kondisi 10 , putaran ketiga

Dari hasil pengamatan di atas, maka dapat disimpulkan bahwa untuk mencapai satu putaran penuh kedua motor memiliki jumlah langkah yang berbeda. Untuk motor I hanya memerlukan 20 langkah dalam satu putaran dengan tiap langkah ditempuh 18, sedangkan untuk motor 2 memerlukan 50 langkah untuk satu kali putaran, dengan tiap langkah ditempuh $7.2^{\circ}$

Pengendalian motor stepper ini dirancang khusus untuk berjalan pada kecepatan rendah atau membatasi keceptan maksimum. Hal ini dikarenakan kecepatan motor yang rendah mampu meminimalisasi selip.

Selain itu karakteristik motor yang mampu memegang tenaga putaran (holding torque) akan selalu memegang posisi motor.
Maka saat motor mencapai posisi terakhir motor tidak dapat digerakan hal ini dikarenakan pulsa terakhir yang masuk pada motor tetap dijaga.

Untuk memperkecil permasalahan dalam motor, kecepatan diatur konstan agar panas yang dihasilkan setelah melakukan putaran tidak terlalu tinggi. Semakin cepat perputaran motor, semakin tinggi suhu motor. Motor stepper dirancang berjalan pada suhu ( $\left.50^{\circ}-90^{\circ} \quad \mathrm{C}\right)$. Bagaimanapun, terlalu banyak putaran menyebabkan pemanasan berlebihan dan kerusakan pada isolasi motor dan lilitan.

\section{Perhitungan Sudut Putar Motor} Motor stepper dalam 1 kali putar mencapai sudut $360^{\circ}$.

Dari hasil pengamatan diperoleh 1 revolusi motor 1 hanya bergerak sebanyak 20 langkah.

$$
\begin{aligned}
& \text { Sudut }=360 \% \text { n rotor } \\
& \begin{array}{l}
360 \% 20=18^{\circ} \\
\text { Dari hasil pengamatan }
\end{array}
\end{aligned}
$$
diperoleh 1 revolusi motor 2 hanya bergerak sebanyak 50 langkah.

Sudut $=360 \% \mathrm{n}$ rotor

$360 \% 50=7.2^{\circ}$ 
Dari hasil perhitungan didapat bahwa motor 1 dan 2 memiliki jenis yang sama yaitu unipolar namun jumlah rotor yang tersusun di dalamnya berbeda, sehingga untuk mencapai 1 putaran penuh juga ditempuh berbeda sesuai dengan tiap sudut langkah yang mampu dicapainya.

\section{G. Pengamatan Kerja Rangkaian}

\section{Kendali Secara Elektronis}

Rangkaian kendali terdiri dari komponen-komponen elektronik arus lemah dimana salah satunya adalah Transistor. Transistor mempunyai 3 kutub yakni Kolektor, Basis, dan Emitor. Aplikasi Transistor disini bukanlah sebagai penguat, melainkan sebagai saklar elektronik, sehingga bila basis transistor menerima arus (berlogika tinggi) maka seolah-olah antara kolektor dan basis akan terhubung singkat, sedangkan bila arus basis 0 (berlogika rendah), maka antara kolektor dan emitor berperan sebagai Resistor yang besarnya tak terhi dihubungkan menggunakan port parallel, yang memberikan tegangan output ke driver sebesar $5 \mathrm{~V}$.

2.Kedua motor memiliki jumlah rotor yang berbeda sehingga tiap langkah masing-masing motor juga berbeda. Untuk motor 1 memerlukan 20 langkah untuk menempuh 1 putaran penuh, sedangkan untuk motor 2 memerlukan 50 langkah untuk menempuh 1 putaran penuh.

3.Motor stepper bergerak berdasarkan urutan pulsa dengan logika bit biner dari port printer yang masuk pada rotor sesuai perintah software motor stepper.

4. Gerakan kedua motor secara bersamaan merupakan hasil dari penjumlahan kondisi kedua motor dengan logika biner. Untuk bergerak ke arah kanan jumlah biner awal yang digunakan adalah (0001.0001) atau 17 kemudian jumlahkan dengan nilai 17 , begitu seterusnya untuk kondisi selanjutnya. Untuk bergerak ke arah kiri kurangkan biner awal yang digunakan adalah (1000.1000) atau 136. kemudian kurangi nilai 17 , begitu seterusnya untuk kondisi selanjutnya.

\section{Kesimpulan Dan Saran}

\section{A. Kesimpulan}

1.Antara komputer dengan perangkat pengendali motor stepper

\section{B. Saran}

1.Agar mengurangi ketergantungan menggunakan komputer sebagai pusat pengendali maka fungsi komputer 
dapat digantikan dengan rangkaian mikrokontroler.

2.Perintah melalui komunikasi parallel tidak bisa dilakukan secara bersama-sama, untuk pengembangannya diharapkan bisa dilakukan secara bersama-sama sehingga bisa mempercepat proses kerja.

3. Koneksi antara perangkat kendali dengan komputer dapat diganti dengan radio agar dapat memangkas penggunaan kabel dan mampu mengontrol pada jarak yang lebih jauh.

\section{DAFTAR PUSTAKA}

Alexander, Hengky M., Belajar Sendiri Membangun Sistem Database dengan Visual Basic 6.0 dan Access 2000, Elex Media Komputindo, Jakarta, 2003.

Budiharto, Widodo dan Sigit Firmansyah, Elektronika Digital dan Mikroprosesor, Penerbit ANDI, Yogyakarta, 2005.

Endra Pitowarnao, Mikroporosesor \& Interface II, PENS-ITS Surabaya, 1994.

Yuhefizar, Tutorial Komputer dan Jaringan,

http://www.ilmukomputer.com, 2003.

\section{Baskar Gupta, Stepper motor control trough parallel port, http://www.kodeproject.com, 17 Mei 2007.}

Aswan Hamonangan, Resistor, http://www.electroniclab.com, $17 \mathrm{Mei}$ 2005.

Aswan Hamonangan, Transistor, http://www.electroniclab.com, $17 \mathrm{Mei}$ 2005.

Aswan Hamonangan, Dioda, http://www.electroniclab.com, $17 \mathrm{Mei}$ 2005.

Jones Douglas, Stepping Motor Types, http://www.cs.euoa.edu, 2006.

Annonameous,

IN400I-IN4007, http://www. fairchildsemi.com/ds,

1 September 2007.

Annonameous, Linear Integrated Circuit, http://www. contek-ic.com,

September 2007.

Thomson, NPN Silicon Transistor, http://www.datasheetarchive.com, $19 \mathrm{Mei}$ 2007.

Annonameous, Interfacing the Standard Parallel Port,

http: www besundlogic org spp parallel.ht m, 5 september 2007

Jan Axelsons, Inpout32.dll for Windows, http://www.logix tu net parallelportl.htm, 10Mei 2007. 